\title{
Patient-specific assessment of hemodynamics by computational fluid dynamics in patients with bicuspid aortopathy
}

\author{
Naoyuki Kimura, MD, PhD, ${ }^{\text {a }}$ Masanori Nakamura, $\mathrm{PhD},{ }^{\mathrm{b}}$ Kenji Komiya, BS, ${ }^{\mathrm{b}}$ Satoshi Nishi, MD, ${ }^{\mathrm{a}}$ \\ Atsushi Yamaguchi, MD, PhD, ${ }^{\mathrm{a}}$ Osamu Tanaka, $\mathrm{MD}, \mathrm{PhD},{ }^{\mathrm{c}}$ Yoshio Misawa, $\mathrm{MD}, \mathrm{PhD},{ }^{\mathrm{d}}$ \\ Hideo Adachi, $\mathrm{MD}, \mathrm{PhD},{ }^{\mathrm{a}}$ and Koji Kawahito, $\mathrm{MD}, \mathrm{PhD}^{\mathrm{d}}$
}

\begin{abstract}
Objective: Hemodynamics related to eccentric blood flow may factor into the development of bicuspid aortic valve aortopathy. We investigated wall shear stress distribution by means of magnetic resonance imaging-based computational fluid dynamics in patients with a bicuspid aortic valve.

Methods: Included were 12 patients with a bicuspid aortic valve (aortic stenosis, $\mathrm{n}=11$; root enlargement, $\mathrm{n}=1$ ). Three patients with a normal tricuspid aortic valve (arch aneurysm, $\mathrm{n}=1$; descending aortic aneurysm, $\mathrm{n}=2$ ) were included for comparison. The thoracic aorta geometry was reconstructed by means of 3dimensional computed tomography angiography, and the bicuspid aortic valve orifice was modeled. Flow rates at the sinotubular junction and 3 aortic branches were measured at various time points by cine phase-contrast magnetic resonance imaging to define boundary conditions for computational fluid dynamics, and the flow was simulated.
\end{abstract}

Results: Bicuspid aortic valve cusp configurations were type 0 lateral $(n=4)$, type 0 anterior-posterior $(\mathrm{n}=2)$, type $1 \mathrm{~L}-\mathrm{R}(\mathrm{n}=4)$, and type $1 \mathrm{R}-\mathrm{N}(\mathrm{n}=2)$. Abnormal aortic helical flow was seen in the ascending aorta and transverse arch in all patients with bicuspid aortic valves and was right handed in 11 patients $(91 \%)$. No such flow was seen in the patients with tricuspid aortic valves. The patients with bicuspid aortic valves were likely to have jet flow/wall impingement against the greater curvature of the proximal ascending aorta, resulting in remarkably increased wall shear stress around the impingement area.

Conclusions: Computational fluid dynamics simulation is useful for precise evaluation of hemodynamics related to bicuspid aortic valve aortopathy. Such evaluation will advance our understanding of the disease pathophysiology and may facilitate molecular biological investigation. (J Thorac Cardiovasc Surg 2017;153:S52-62)
The bicuspid aortic valve (BAV) is one of the most common congenital cardiac defects, affecting $1 \%$ to $2 \%$ of the general population. ${ }^{1}$ Dilatation of the ascending aorta develops in $50 \%$ of patients with $\mathrm{BAV}^{2,3}$ The pathogenesis of this BAV aortopathy is complex, and both genetic and hemodynamic factors have been implicated. Aside from

\footnotetext{
From the Departments of ${ }^{\mathrm{a}}$ Cardiovascular Surgery and ${ }^{\mathrm{c}}$ Radiology, Saitama Medical Center, and ${ }^{\mathrm{d}}$ Division of Cardiovascular Surgery, Department of Surgery, Jichi Medical University; and ${ }^{\mathrm{b}}$ Department of Mechanical Engineering, Biomechanics Laboratory, Saitama University, Saitama, Japan.

This work was supported by Grants-in-Aid for Scientific Research (C) (K.K., \#26462117, N.K., \#15K10246), Grant-in-Aid for Young Scientists(A) (M.N., \#26702012), and Grants-in-Aid for Challenging Exploratory Research (M.N., \#16K12867) from the Ministry of Education, Culture, Sports, Science and Technology, Japan.

This paper was selected as Plenary Citation at the American Association for Thoracic Surgery Aortic Symposium 2016, New York, New York, May 12-13, 2016.
} 

Abbreviations and Acronyms
$\mathrm{BAV}=$ bicuspid aortic valve
CFD = computational fluid dynamics
$\mathrm{CT}=$ computed tomography
$4 \mathrm{D}=4$-dimensional
MRI = magnetic resonance imaging
PC-MRI $=$ phase-contrast magnetic resonance imaging
TAV $=$ tricuspid aortic valve
$3 \mathrm{D}=3$-dimensional
2D $\quad=2$-dimensional
WSS $=$ wall shear stress

Scanning this QR code will take you to supplemental figures, table, and videos for this article.

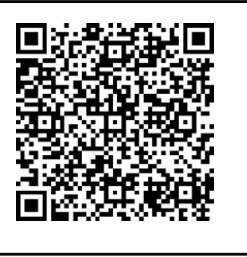

intrinsic vulnerability, the cells and connective tissue in the aortic wall are exposed to eccentric flow jets created by the abnormal valve anatomy. Asymmetric histopathologic changes in patients with BAV with a nondilated ascending aorta support the notion that hemodynamics play an essential role. ${ }^{4}$ We believe that a method by which analysis of high-quality imaging data can be achieved is important for precise, reliable, patient-specific evaluation of abnormal hemodynamics.

Phase-contrast magnetic resonance imaging (PC-MRI) can be used to measure flow velocity accurately and noninvasively. Two-dimensional (2D) cine PC-MRI, which emerged in the late 1980s, permits measurement of blood flow velocity in a designated cross-section of the heart and great vessels at various time points in the cardiac cycle. Time-resolved PC-MRI with velocity encoding of all 3 flow directions and 3-dimensional (3D) anatomic scanning, termed "4-dimensional (4D) flow magnetic resonance imaging (MRI)," has been proven to visualize the 3D flow pattern and hemodynamic forces that act on the aortic wall. ${ }^{5-9}$ Four-dimensional flow MRI allows assessment of aortic flow and wall shear stress (WSS), both of which have been implicated in aortic enlargement. ${ }^{6-8}$

Computational fluid dynamics (CFD) has emerged as a useful tool for clinical assessment of hemodynamics. ${ }^{10-12}$ Although CFD requires some computational modeling, ${ }^{13}$ it provides detailed flow information that surpasses that of traditional imaging modalities such as Doppler echocardiography and MRI.
WSS has gained attention as a local hemodynamic factor that plays a role in vascular events. WSS (or $\tau_{w}$ ) is defined as follows:

$$
\tau_{w}=\mu\left(\frac{\partial \mathbf{u}}{\partial \mathbf{n}}\right)_{\text {wall }}
$$

where $\mu$ is the dynamic viscosity, $\mathbf{u}$ is the flow velocity vector, and $\mathbf{n}$ is the normal velocity vector near the wall. $\left(\frac{\partial \mathbf{u}}{\partial \mathbf{n}}\right)_{\text {wall }}$ is the wall shear rate. In quantifying WSS on the basis of 4D flow MRI and CFD data, which are discrete rather than continuous values, it is usually assumed that flow velocity varies linearly with distance from the wall. Under this assumption, the shear rate is calculated by dividing a tangential component of velocity by the distance between the wall and the nearest grid point where the velocity data are derived. The difference between $4 \mathrm{D}$ flow MRI and CFD is illustrated in Figure E1. When 4D flow MRI is used, the vessel is embedded in the Cartesian grids. Accordingly, the distance between the vessel wall where the WSS is to be assessed and the nearest grid point where the velocity is measured varies from place to place. This may result in biased estimates of the WSS. For CFD, however, grid points can be adjusted on demand. Boundaryfitted grids with prism layer meshing allow for equidistant allocation of all grid points used to assess the wall shear rate, that is, all grid points will be of equal distance from the vessel wall. This results in precise assessment of the WSS over the entire vessel wall.

CFD has been used to evaluate the hemodynamics of aortic coarctation associated with BAV. ${ }^{14}$ One of the keys to successfully reproducing patient hemodynamics is specifying the flow boundary conditions in the computational flow domain. Traditionally, CFD has been implemented with generalized flow boundary conditions taken from a clinical database. However, because flow conditions vary from patient to patient, use of generalized flow conditions results in unrealistic magnitude and distribution of the WSS. ${ }^{15}$ More accurate hemodynamics simulation can be achieved with the use of patient-specific flow conditions obtained by means of 2D cine PC-MRI. We conducted a retrospective study in which we tested the feasibility of patient-specific CFD for investigation of individual hemodynamics in patients with BAV. We also compared our findings with those reported previously from 4D flow MRI studies.

\section{MATERIALS AND METHODS}

\section{Study Patients}

The study involved 2 groups of patients. One group comprised 12 patients with BAV who, between October 2014 and January 2016, had undergone elective aortic valve surgery with or without proximal aortic arch replacement for aortic stenosis $(\mathrm{n}=11)$ or root enlargement $(\mathrm{n}=1)$ at Saitama Medical Center, Jichi Medical University (Saitama, Japan) $(\mathrm{n}=11)$, or Jichi Medical 
University (Shimotsuke, Japan) $(\mathrm{n}=1)$. None of these patients had a history of aortic coarctation. The second group comprised 3 patients with a functioning normal tricuspid aortic valve (TAV) with neither aortic root nor ascending aorta dilation and who, also between October 2014 and January 2016, had undergone open or endovascular repair for distal aortic arch aneurysm or descending aortic aneurysm at Saitama Medical Center. These 3 patients were considered control patients. Under approval granted by the Institutional Review Board of Jichi Medical University, we obtained and reviewed patients' clinical charts and our computerized database records.

\section{Classification of Valve Configuration and Bicuspid Aortopathy}

The morphology of each patient's aortic valve had been carefully assessed preoperatively by means of echocardiography and was confirmed intraoperatively. Cusp configuration type was determined on the basis of the classification system of Sievers and Schmidtke. ${ }^{16}$ The BAV aortopathy was classified according to the types proposed by Fazel and colleagues ${ }^{17}$ and Kang and colleagues ${ }^{18}$ : type 0 , normal aorta; type 1 , aortic root dilatation; type 2 , aortic enlargement involving the tubular portion of the ascending aorta; and type 3, diffuse involvement of both the entire ascending aorta and the transverse aortic arch. Dilation of the aortic segment (aortic root, tubular portion of the ascending aorta, and aortic arch) was diagnosed if the segment diameter was greater than $40 \mathrm{~mm}$. The aortopathy pattern was determined on the basis of gated, thin-slice computed tomography (CT) imaging data and 3D reconstruction of the aortic root, tubular ascending aorta, and aortic arch. ${ }^{19}$

\section{Computer Simulation of Blood Flow}

The procedural steps performed for computerized patient-specific simulation of blood flow are diagrammed in Figure 1. The 3D geometry of the aorta was reconstructed from preoperative CT angiography data. Contrast CT angiography was performed with an Aquilion (Toshiba Medical Systems, Otawara, Japan) or SOMATOM Definition Flash (Siemens, Munich,
Germany) scanner. Spatial resolution was $0.65 \times 0.65 \times 0.5 \mathrm{~mm}$. Geometric reconstruction was implemented with commercially available imaging software, AMIRA (ver. 5.4.2, Maxnet, Tokyo, Japan), and the surface was smoothed with a commercially available digital sculpting program, 3DCoat (ver. 4.1.17d, Pilgway, Kiev, Ukraine). A virtual bicuspid valve orifice was created with computer-aided design software, Creo Parametric (PTC, Needham, Mass) and applied at the level of the sinotubular junction. For each patient, orientation of the bicuspid valve and shape of the orifice were determined echocardiographically and intraoperatively. In most patients, the aortic valve was severely calcified and thus did not open and close or change in shape during the cardiac cycle.

Flow rates at various time points in the cardiac cycle were measured at the sinotubular junction, supra-aortic branches, and descending aorta in each patient by means of 2D cine PC-MRI. MRI was performed on a 3.0-T Vantage Titan (Toshiba Medical Systems) or Magnetom Skyra (Siemens) system. Standard clinical MRI settings were used: repetition time, 33 (43) ms; echo time, 5.4 to $6.0(2.5) \mathrm{ms}$; velocity encoding range, $300(500) \mathrm{cm} / \mathrm{s}$; flip angle, $30(30)^{\circ}$; slice thickness, 5 (10) mm; matrix, $192 \times 192(256 \times 256)$; and field of view $32 \times 24(30 \times 30) \mathrm{cm}$. All measurements were made on breath-hold images obtained after maximum expiration. The $\mathrm{R}$ wave on electrocardiogram was used to trigger the MRI acquisition. The flow rate at each time point was calculated by integration of axial velocities within a manually chosen vessel lumen of interest. Although the flow rates at all inlets and outlets of the aorta were measured, the continuity equation was not well satisfied in some patients because of measurement errors. In such cases, flow rates were estimated on the basis of physiology, and the rest were interpolated from the reliable data according to the conservation of mass principle. A moving average was used to smooth the flow rate data, and a cubic spine was used for interpolation because the time points used for flow simulation were closer together than the time points reflected in the MRI data set. Flow rate curves obtained in 1 case (patient 11) are shown in Figure E2. Similar curves were plotted for all patients and used for the simulations.

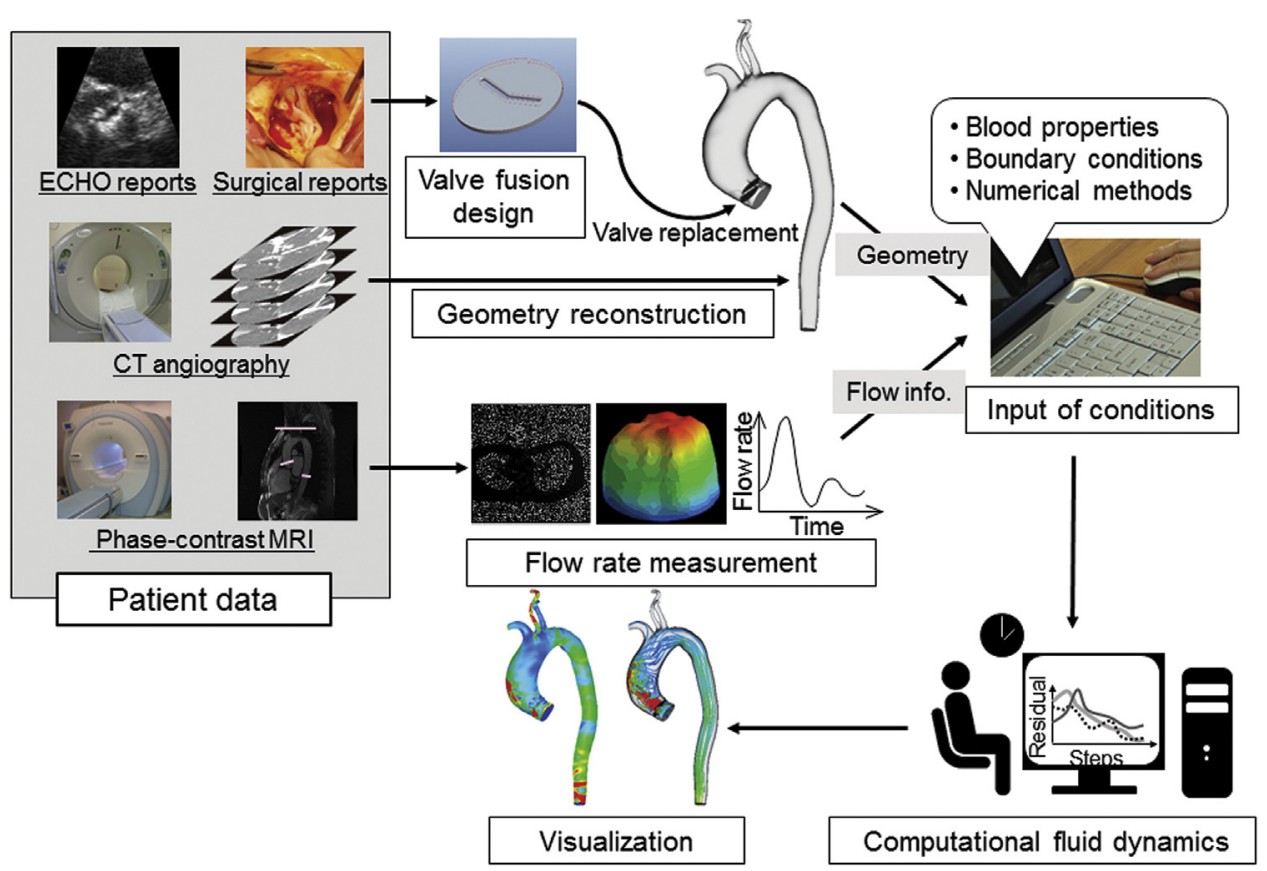

FIGURE 1. Flow diagram of patient-specific blood flow simulation. A thoracic aorta model was reconstructed from CT images. Designed on the basis of preoperative echocardiography and surgical reports, the aortic valve orifice was modeled and fitted to the root of the aorta model. Patient-specific hemodynamics were simulated with boundary conditions of flow-rate data acquired from PC-MRI. The simulated flow data are visualized with streamlines and contour plots of WSS. CT, Computed tomography; MRI, magnetic resonance imaging. 
Computational meshes were generated with SCRYU ver. 12 (Software Cradle Co, Tokyo, Japan), which is thermo-fluid simulation software used for CFD analysis. Five layers of a prism mesh were created near the vessel wall, and the remaining geometry was filled with tetrahedral meshes. Special care was taken in meshing the bicuspid valve orifice, where the passageway is extremely narrow. The total number of meshes was approximately 1 million.

Blood was treated as an incompressible Newtonian fluid with a density of $1.06 \times 10^{3} \mathrm{~kg} / \mathrm{m}^{3}$ and a viscosity of $4.0 \times 10^{-3} \mathrm{~Pa} \cdot \mathrm{s}$. CFD was implemented with SCRYU ver. 12 (Software Cradle Co). No turbulence model was used. Time was marked at increments of $1 \times 10^{-4}$ seconds or $5 \times 10^{-4}$ seconds. The convergence criterion was $1 \times 10^{-4}$. Boundaries for the measured and interpolated flow rates were the aortic branches and the ascending aorta. A no-slip condition was applied at the wall, with the vessel wall assumed to be rigid. A zero pressure condition was imposed at the end of the descending aorta. The flow simulation was carried out over 4 cardiac cycles to obtain cyclically repeatable flow patterns.

Simulations to test what-if scenarios also were performed. First, tricuspid aortic stenosis and the resulting hemodynamics were simulated in the control group patients. Severe stenosis was modeled as a circular orifice that covers one third of the aortic annulus area. The virtual orifice was created with computer-aided design software and applied at the level of the sinotubular junction. Second, hemodynamics after valve replacement were simulated under 2 possible BAV conditions: that of aortic dilatation in a patient (patient 10) given a large biological valve with no flow resistance and that of no aortic dilatation in a patient (patient 11) given a biological valve, after which mild postoperative aortic stenosis developed. In the large valve replacement scenario, the BAV was removed and the aortic valve was considered fully open. In the second scenario, mild postoperative aortic stenosis was modeled by creation of a virtual circular orifice that covered two thirds of the aortic annulus area and was applied at the level of the sinotubular junction. The simulation conditions, including the boundary conditions, in these scenarios were the same as the original simulations in each patient.

\section{Statistical Analyses}

All values are expressed as mean \pm standard deviation. Between-group differences were analyzed by chi-square, Fisher exact, unpaired $t$, or Mann-Whitney $U$ test, as appropriate. The maximum WSS and percentage of increased WSS distribution were compared between the 2 control conditions (normal tricuspid valve with nondilated ascending aorta and simulated tricuspid stenosis with nondilated ascending aorta) and the BAV condition. Bonferroni correction was used for multiple comparisons with increased WSS defined as greater than $5 \mathrm{~Pa}$. Correlation between maximum WSS with unadjusted/adjusted aortic diameter and age was assessed in the BAV group by Spearman's rank correlation coefficient. SPSS Statistics version 23.0 (IBM Corporation, Armonk, NY) was used for all analyses.

\begin{tabular}{|c|c|c|c|c|c|c|}
\hline & Patient 1 & Patient 2 & Patient 3 & Patient 4 & Patient 5 & Patient 6 \\
\hline $\begin{array}{l}\text { Age, sex } \\
\text { AS/ AI }\end{array}$ & $\begin{array}{c}41 \text { years, male } \\
\text { AS/mild Al }\end{array}$ & $\begin{array}{c}46 \text { years, female } \\
\mathrm{AS} / \mathrm{no} \mathrm{Al}\end{array}$ & $\begin{array}{c}64 \text { years, male } \\
\text { AS/ trivial Al }\end{array}$ & $\begin{array}{c}66 \text { years, male } \\
\text { AS/trivial Al }\end{array}$ & $\begin{array}{l}37 \text { years, male } \\
\text { no AS/trivial Al }\end{array}$ & $\begin{array}{l}77 \text { years, male } \\
\text { AS/trivial Al }\end{array}$ \\
\hline Siever's class & Type O lat & Type 0 lat & Type 0 lat & Type 0 lat & Type 0 ap & Type 0 ap \\
\hline \multicolumn{7}{|l|}{ AVA $\left(\mathrm{cm}^{2}\right)$} \\
\hline \multicolumn{7}{|l|}{$\begin{array}{l}\text { Type of } \\
\text { bicuspid } \\
\text { aortopathy }\end{array}$} \\
\hline & Patient 7 & Patient 8 & Patient 9 & Patient 10 & Patient 11 & Patient 12 \\
\hline $\begin{array}{l}\text { Age, sex } \\
\text { AS / Al }\end{array}$ & $\begin{array}{c}53 \text { years, female } \\
\text { AS/trivial Al }\end{array}$ & $\begin{array}{c}67 \text { years, female } \\
\text { AS/trivial Al }\end{array}$ & $\begin{array}{c}68 \text { years, male } \\
\text { AS/trivial Al }\end{array}$ & $\begin{array}{l}68 \text { years, male } \\
\text { AS/moderate Al }\end{array}$ & $\begin{array}{l}64 \text { years, male } \\
\text { AS/trivial Al }\end{array}$ & $\begin{array}{c}69 \text { years, male } \\
\text { AS/mild Al }\end{array}$ \\
\hline Siever's class & Type 1 L-R & Type 1 L-R & Type 1 L-R & Type 1 L-R & Type 1 R-N & Type $1 \mathrm{R}-\mathrm{N}$ \\
\hline AVA $\left(\mathrm{cm}^{2}\right)$ & 0.91 & 0.77 & & 1.62 & & 1.05 \\
\hline $\begin{array}{l}\text { Type of } \\
\text { bicuspid } \\
\text { aortopathy }\end{array}$ & & & 0 & 3 & 0 & \\
\hline
\end{tabular}

FIGURE 2. Anatomic information. For each patient, anatomic information, including valve morphology and aortopathy, was recorded. Cusp configuration was described according to the classification system of Sievers and Schmidtke. ${ }^{16}$ BAV aortopathy phenotype was expressed according to the clustering system advocated by Fazel and colleagues ${ }^{17}$ and Kang and colleagues ${ }^{18}$ : type 0 , normal aorta; type 1, aortic root dilation; type 2, aortic enlargement involving the tubular portion of the ascending aorta; and type 3, diffuse involvement of both the entire ascending aorta and the transverse aortic arch. AS, Aortic stenosis; $A I$, aortic insufficiency; lat, lateral; $a p$, anterior-posterior; $A V A$, aortic valve area; $N A$, not applicable; $L$, left coronary sinus; $R$, right coronary sinus; $N$, noncoronary sinus. 

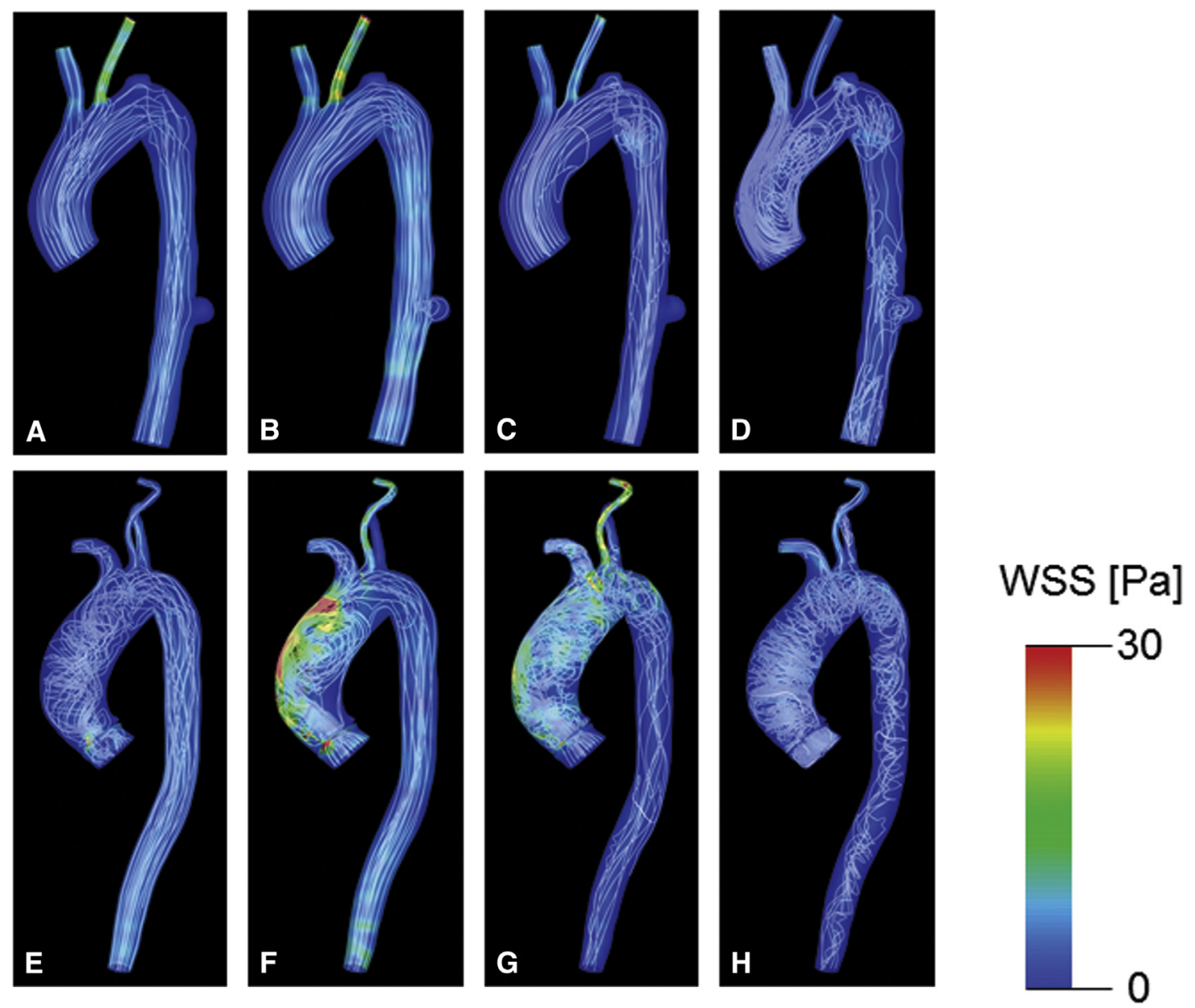

FIGURE 3. Representative temporal variations in WSS and streamlines during a cardiac cycle. Imaging data of patients with a normal TAV orifice are shown at the top (A-D), and imaging data of patients with bicuspid aortic stenosis are shown at the bottom (E-H). Data were obtained at different times in the cardiac cycle: early systole (A, E), mid-systole (B, F), late systole (C, G), and mid-diastole (D, F). WSS, Wall shear stress; Pa, pascal.

\section{RESULTS}

\section{Patient Characteristics}

Patients' clinical characteristics and measures of the severity of aortic disease are shown per group in Table E1. There was no between-group difference in age, sex, weight, or body surface area. Aortic insufficiency was mild $(n=2)$ or moderate $(n=1)$ in $25 \%$ of the patients with BAV. There was no between-group difference in left ventricular diastolic and systolic dimensions or left ventricular ejection fraction. The 3 patients with TAV were significantly taller than those with BAV. Mild aortic stenosis was present in only 1 of the 12 patients with BAV (patient 5); the mean pressure gradient was $4.5 \mathrm{~mm} \mathrm{Hg}$, and root dilation was observed. Although there were no significant between-group differences in absolute aortic diameter at each aortic segment, the aortic diameter indexed to body surface area at the transverse arch was significantly greater $(P=.036)$ in those with BAV than in those with TAV. The diameter of the mid-tubular ascending aorta tended to be greater in the BAV group than in the control group $(P=.15)$.
Aortic valve fusion types and 3D CT angiography data are shown for the patients with BAV in Figure 2. Cusp configurations were as follows: type 0 lateral, $\mathrm{n}=4$; type 0 anterior-posterior, $\mathrm{n}=2$; type $1 \mathrm{~L}-\mathrm{R}, \mathrm{n}=4$; and type 1 $\mathrm{R}-\mathrm{N}, \mathrm{n}=2$. BAV aortopathy phenotypes were as follows: type $0, \mathrm{n}=3$; type $2, \mathrm{n}=7$; and type $3, \mathrm{n}=2$. There was no type $1 \mathrm{BAV}$ aortopathy.

\section{Patient-Specific Simulation of Hemodynamics}

Representative hemodynamic patterns in a TAV case and BAV case are shown in Figure 3 (Videos 1 [TAV] and 2 [BAV]). Spatial distribution of the WSS streamlines at 4 different time points in the cardiac cycle is shown. The streamlines were obtained by computing and plotting the trajectories of fluid elements within the aorta. In the patient with TAV, blood flow in the aorta was mostly laminar during systole, although the flow started to spiral in late systole (Figure 3, A-C). By the onset of diastole, axial flow had weakened and secondary helical flow dominated the entire aorta (Figure 3,D). WSS at the aortic trunk was relatively low $(<5 \mathrm{~Pa})$ throughout the cardiac cycle. 


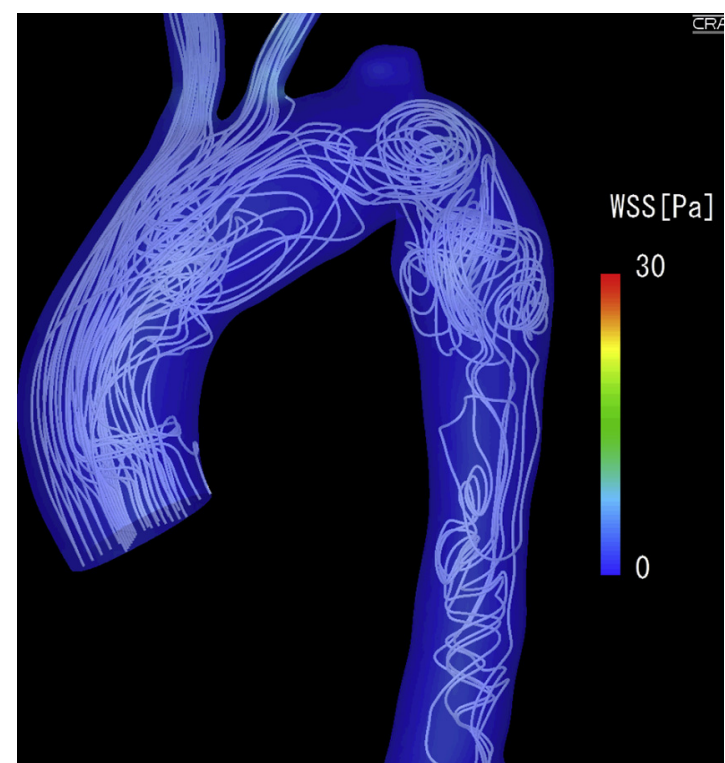

VIDEO 1. Representative CFD-generated hemodynamic pattern in a patient with a normal tricuspid valve. Video available at: http://www. jtcvsonline.org/article/S0022-5223(17)30017-X/addons.

Flow patterns in the patient with BAV varied markedly, especially during systole. Blood flow in the ascending aorta was helical during early systole (Figure 3,E). As systole progressed, an inflow jet developed as the blood passed through the narrow aortic orifice. At peak systole, the velocity of the jet reached $4 \mathrm{~m} / \mathrm{s}$. The jet impinged against the greater curvature of the proximal ascending aorta and split into 2 flows: one traveling upward and rubbing against the greater curvature and the other traveling

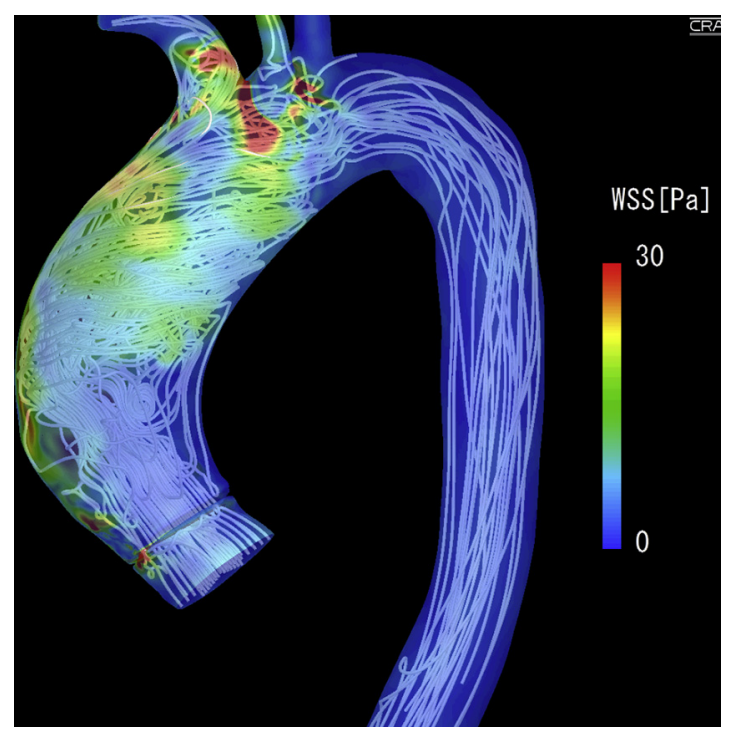

VIDEO 2. Representative CFD-generated hemodynamic pattern in a patient with bicuspid stenosis. Video available at: http://www.jtcvsonline. org/article/S0022-5223(17)30017-X/addons. downward to the aortic valve, creating a recirculation eddy between the jet and the wall (Figure 3,F). During late systole, the paths of the streamlines in the ascending aorta appeared complex and tortuous (Figure 3,G). As was the case in the patient with a normal TAV, WSS in the patient with a BAV was relatively low during early systole. However, WSS was extremely high at the greater curvature of the proximal ascending aorta in the vicinity of the jet impingement (Figure 3,F). Progression of systole resulted in expansion of the abnormally large WSS region (Figure 3, G). During late systole, complex WSS distribution was observed.

Representative images of blood flow during early to mid-systole are shown in Figure 4. In the patients with TAV, there was no helical flow in the thoracic aorta (Figure 4, A). Abnormal helical flow was seen in the ascending aorta and transverse arch in all patients in the BAV group, and right-handed helical blood flow was documented in $11(91 \%)$ of these patients (Figure 4, B). Left-handed helical flow was seen in the remaining patient (patient 1) (Figure 4,C). Contour plots of WSS at systole (anteroposterior and posteroanterior views) are shown for all patients in Figure 5. In the BAV cases, WSS was greatest mainly in the greater curvature of the proximal ascending aorta (Figure 5,C), but WSS was not increased in the thoracic aorta in any TAV case (Figure 5, A). The WSS distribution pattern did not differ significantly in relation to the various valve configurations. Rather, WSS tended to be high in the proximal portion of the ascending aorta when the ascending aorta deviated laterally (in patients 2-5, 8, and 10 vs patients 1 and 11), and WSS was not particularly increased in the ascending aorta in 1 patient with left-handed helical flow (patient 1). The patient with root dilation and mild aortic stenosis (patient 5) also showed increased WSS distribution in the greater curvature of the ascending aorta. CFD simulations of tricuspid aortic stenosis are shown in Figure 5, B (Video 3). The data showed that tricuspid stenosis also causes increased WSS distribution in the greater curvature of the ascending aorta. Maximum WSS and percentage of increased WSS area in the ascending aorta are shown in Figure 6. Compared with values in the normal TAV cases, the BAV cases showed significantly increased maximum WSS $(P=.012)$ and increased WSS area $(P=.012)$. Although simulated tricuspid stenosis, in comparison with normal TAV, yielded increased the maximum WSS and WSS distribution, the differences were not significant. Negative correlation was found between maximum WSS and unadjusted/adjusted tubular aortic diameter (Figure 7) and between maximum WSS and age (Figure E3).

WSS distributions at peak systole in BAV cases (patients 10 and 11) before and after valve replacement are shown in Figure E4. WSS decreased even after implantation of a 

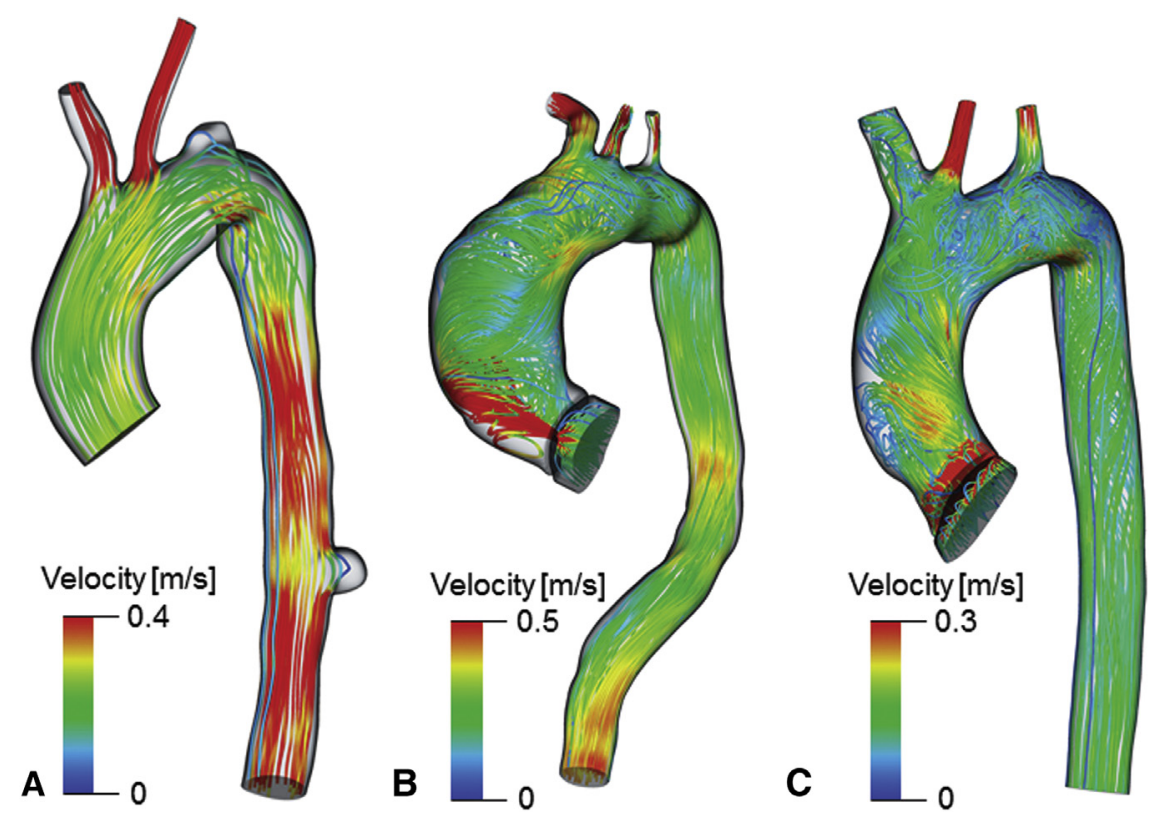

FIGURE 4. Representative images of the helical flow in the ascending aorta at early-mid systole. A, TAV with no helical flow. B, Bicuspid aortic stenosis with right-hand helical flow. C, Bicuspid aortic stenosis with left-hand helical flow.

biological valve with mild postoperative aortic stenosis in the BAV case without aortic enlargement.

\section{DISCUSSION}

Widespread availability of powerful computers together with efficient pre- and postprocessing facilities has allowed the use of CFD in cardiovascular research. ${ }^{10-}$ 12,20,21 Combined use of CFD and imaging modalities allows for patient-specific simulation of hemodynamics, and by this, we are able to understand the pathogenesis of vascular abnormalities in individual patients. In the present study, we used CT for geometric reconstruction and PC-MRI for acquisition of the flow boundary conditions. The BAV orifice was modeled with the use of computeraided design software. The simulated flow patterns, in particular, the helical flow that developed, agreed with reported in vivo MRI-based observations in both normal ${ }^{22}$ and BAV cases, ${ }^{7}$ confirming successful characterization of the aortic flow by our CFD method. We also showed increased WSS in the greater curvature of the ascending aorta of patients with tricuspid stenosis. In addition, maximum WSS in the BAV cases was found to correlate negatively with tubular aortic diameter and age. These data suggest that increased WSS may promote aortic dilatation particularly in younger patients with BAV with greater wall impingement.

Four-dimensional flow MRI is well established for the analysis of cardiovascular circulation hemodynamics. Involvement of hemodynamic factors in the development of BAV aortopathy has been suggested by the results of the pioneering 4D flow MRI-based research. ${ }^{5-9} \mathrm{~A}$ more time-efficient semiautomated 4D flow MRI analysis system was recently described by Schnell and colleagues. ${ }^{23}$ The major findings reported from 4D flow MRI studies include (1) abnormal, eccentric flow and asymmetrically elevated WSS in the ascending aorta in patients with $\mathrm{BAV}^{5-8}$; (2) abnormal, right-handed helical flow in the ascending aorta in these patients ${ }^{7}$; and (3) the cusp morphology that seems to influence the flow jet pattern, ${ }^{6-8}$ complex WSS distribution in the ascending aorta, ${ }^{6-8}$ and specific types of aortic dilatation. ${ }^{7,8}$ We confirmed the abnormal, eccentric flow and the asymmetrically elevated WSS in the ascending aorta and abnormal right-handed flow. Ninetyone percent of our BAV cases had right-handed helical flow, which was in keeping with the finding reported by Bissell and colleagues ${ }^{7}$ (72\% [69/95] of BAV cases had righthanded helical flow, 11\% [10/95] had normal flow, 13\% [12/95] had complex flow, and 4\% [4/95] had left-handed helical flow). ${ }^{7}$ Regarding the relation between cusp morphology and the flow jet pattern, Barker and colleagues ${ }^{6}$ reported that an eccentric outflow jet results in increased WSS at the right-anterior wall in patients with R-L fusion-type BAV and at the right-posterior wall in patients with R-N fusion-type BAV. Furthermore, Mahadevia and colleagues $^{8}$ reported dilatation of the aortic root only (type 1) or dilatation involving the entire ascending aorta and arch (type 3) in the majority of the R-N fusion-type BAV cases (87\%) but was generally absent in the patients with R-L fusion-type BAV (type 2, 87\%), and differences in aortopathy type between these 2 morphology types were associated with altered flow displacement in the proximal and mid-ascending aorta. ${ }^{8}$ Three of our 4 patients with 


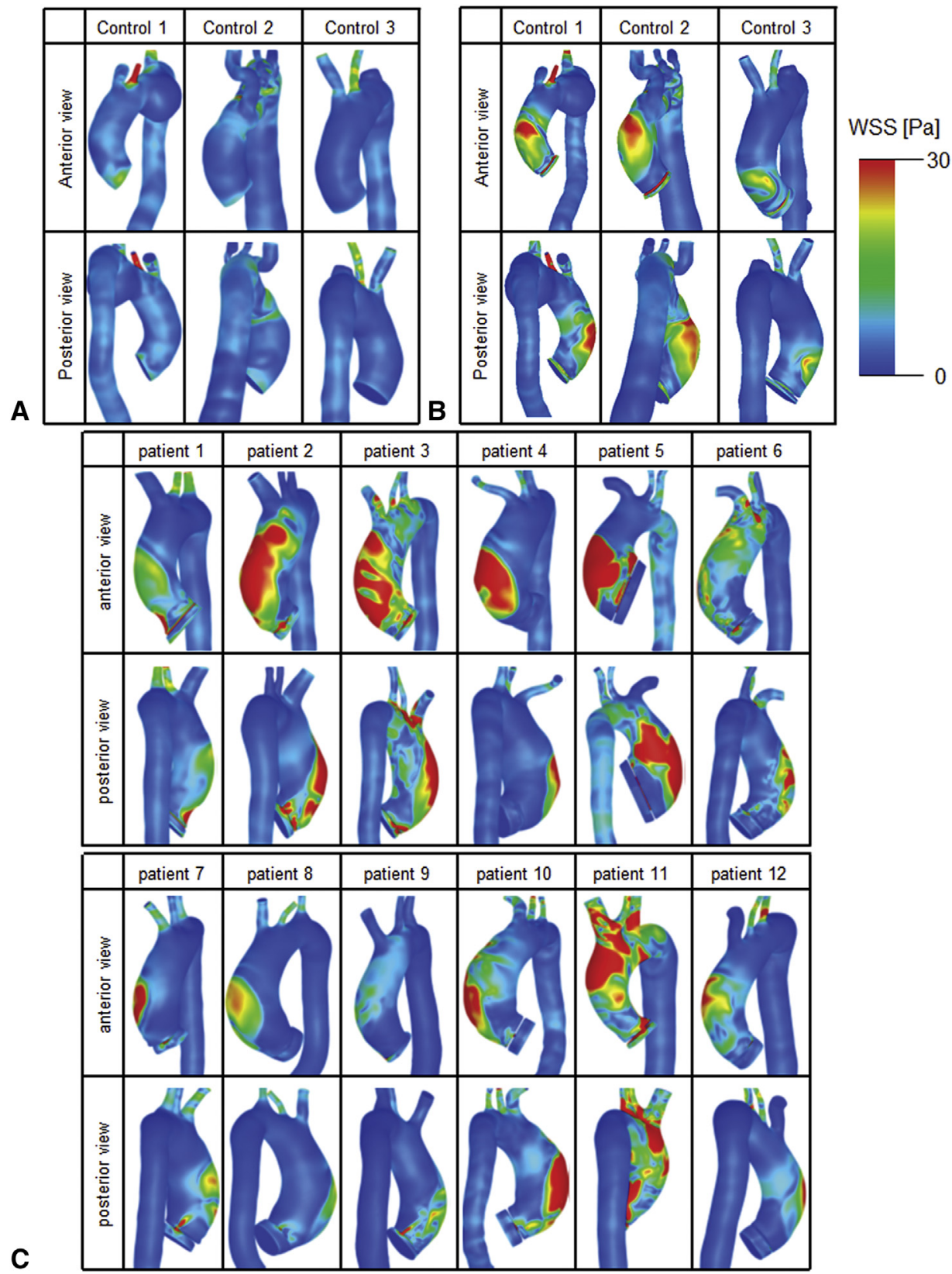

FIGURE 5. Anterior and posterior views of the contour plots of WSS at peak systole. A, Simulation for the 3 patients with a normal TAV. B, Simulation for 3 patients with tricuspid stenosis. C, Simulation for 12 patients with BAV. WSS, Wall shear stress; $P a$, pascal.

R-L fusion-type BAV had an area of increased WSS in the right anterior wall, and 1 of the 2 patients with R-N fusiontype BAV had increased WSS in the right posterior wall. Further investigation into the relation between valve morphology and hemodynamic abnormalities is needed, ideally in a large-scale study.

Despite recently improved outcomes, ${ }^{24}$ aortic dissection remains a serious cardiovascular emergency, and the mortality rate is high. BAV is known to predispose patients to aortic dissection, with the likelihood of dissection onset increasing as the aortic enlargement progresses. The prevalence of ascending aorta dilation and the rate of progression are greater in patients with BAV than in patients with TAV with a dilated ascending aorta. Accordingly, these patients face an increased risk of dissection and at a younger age. $^{3}$ Etz and colleagues ${ }^{25}$ reported pathologic characteristics of acute type A aortic dissection complicated with BAV. Compared with TAV cases, BAV cases tend to be young (46.7 vs 61.6 years, $P<.001$ ) and entry is more often in the aortic root $(31.3 \%$ vs $6.3 \%, P<.001) .{ }^{25}$ Eight of our 12 BAV cases (patients $2-5,7,8,10$, and 12 ) had remarkably increased WSS predominantly in the greater curvature 


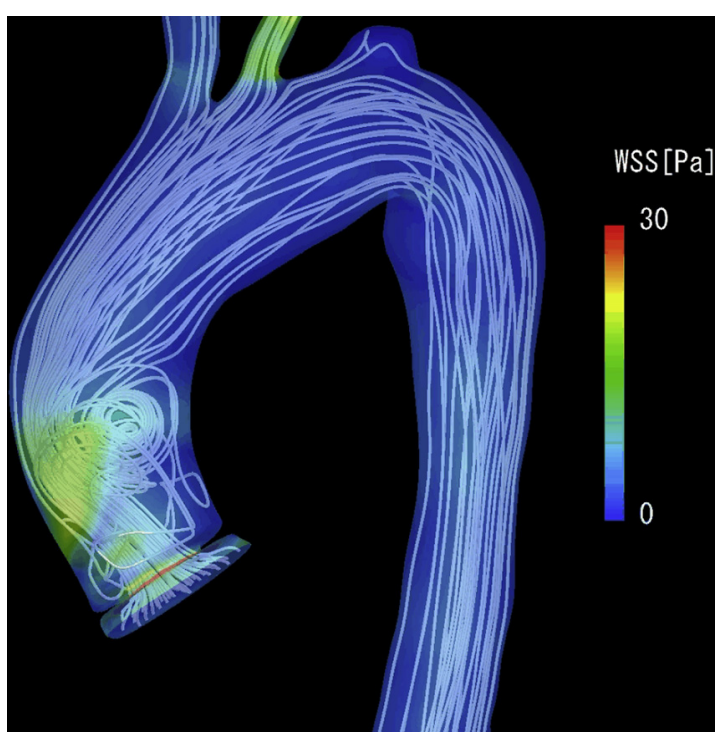

VIDEO 3. Representative CFD-generated hemodynamic pattern in a patient with tricuspid stenosis. Video available at: http://www.jtcvsonline. org/article/S0022-5223(17)30017-X/addons.

comprising the proximal to mid-portion of the ascending aorta. This finding may explain why entry in the proximal portion of the aorta is seen more often in patients with BAV than in other patients. Barker and colleagues ${ }^{6}$ described the fusion type-specific wall/jet impingement and the resulting abnormal WSS distribution in BAV cases. ${ }^{6}$ As shown in Figure 3, WSS is high in the area surrounding the wall/jet impingement area. Our CFD simulation clearly demonstrated a wall/jet impingement area and increased WSS in the surrounding area.

Previous 4D flow MRI studies have shown areas of elevated WSS in the nondilated or mildly dilated ascending aorta in healthy individuals with a functionally normal $\mathrm{BAV}^{9}$ and in pediatric and young adult patients with $\mathrm{BAV}^{26}$ Our 3 patients with no aortopathy (patients 1,9 , and 11) had an area of increased WSS in the ascending aorta. It remains controversial whether a threshold exists for prophylactic resection of the ascending aorta in patients with BAV undergoing aortic valve surgery. Few studies have reported the predissection diameter of the ascending aorta in patients with BAV. The recent American College of Cardiology/American Heart Association guideline recommends $45 \mathrm{~mm}$ as a Class IIa threshold for replacement of the ascending aorta in patients with BAV undergoing aortic valve replacement. ${ }^{27}$ Aggressive resection even at a smaller diameter could be considered on the basis of a patient's risk, CT imaging data, and patient-specific hemodynamic analysis when this becomes clinically available. One of the key findings of our study is that patients with BAV with a laterally deviated proximal ascending aorta were more likely to have high WSS. Thus, BAV cases with a laterally deviated ascending aorta should be carefully followed up even if valve impairment is only mild or moderate. Although our simulation data showed that valve replacement may decrease WSS in patients with BAV, the velocity profile and flow type of the aortic inflow are influenced by the shape of the orifice of the implanted valve. Further investigation is needed to assess postoperative flow dynamics.
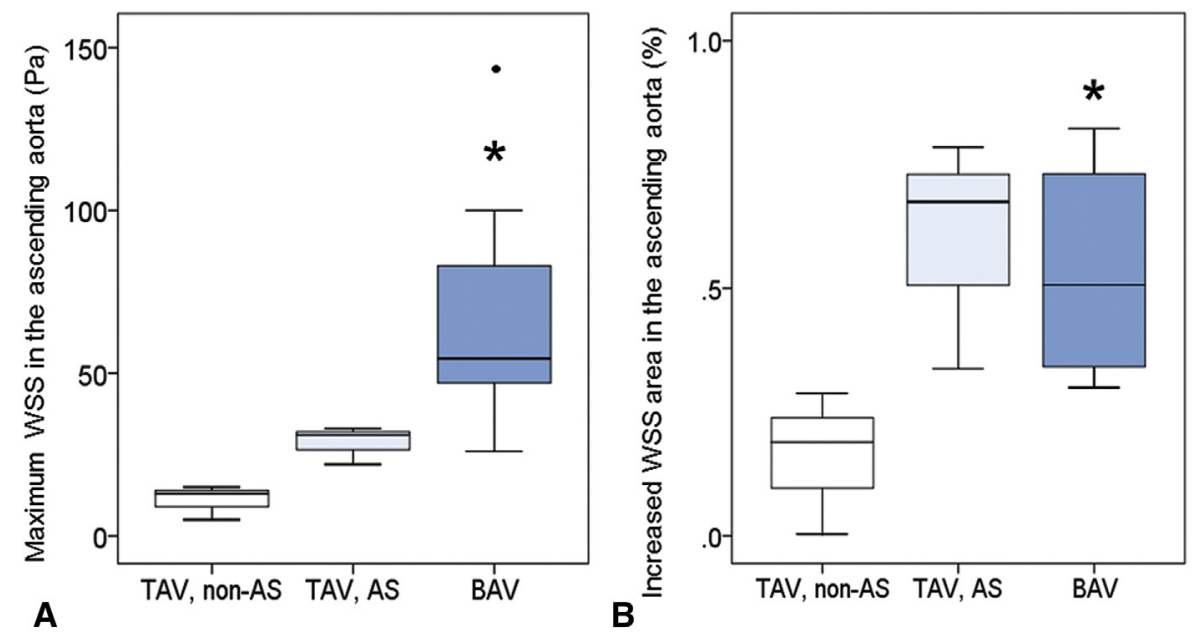

FIGURE 6. Comparisons of hemodynamic parameters. Maximum WSS (A) and proportion of increased WSS in the ascending aorta (B) were determined by CFD analysis and presented as box plot graphs (TAV, non-AS, $\mathrm{N}=3$, TAV, AS, $\mathrm{N}=3, \mathrm{BAV}, \mathrm{N}=12$ ). The line in the middle of the box indicates the median. The lower and upper edges of the box are the first and third quartiles, respectively. The whiskers show the remainder of the distribution (1.5 $\times$ interquartile range). Outlier is shown as filled circle. Increased WSS was defined as WSS greater than $5 \mathrm{~Pa} . * P<.05$ versus TAV non-AS group. WSS, Wall shear stress; $P a$, pascal; $T A V$, tricuspid aortic valve; $A S$, aortic stenosis; $B A V$, bicuspid aortic valve. 

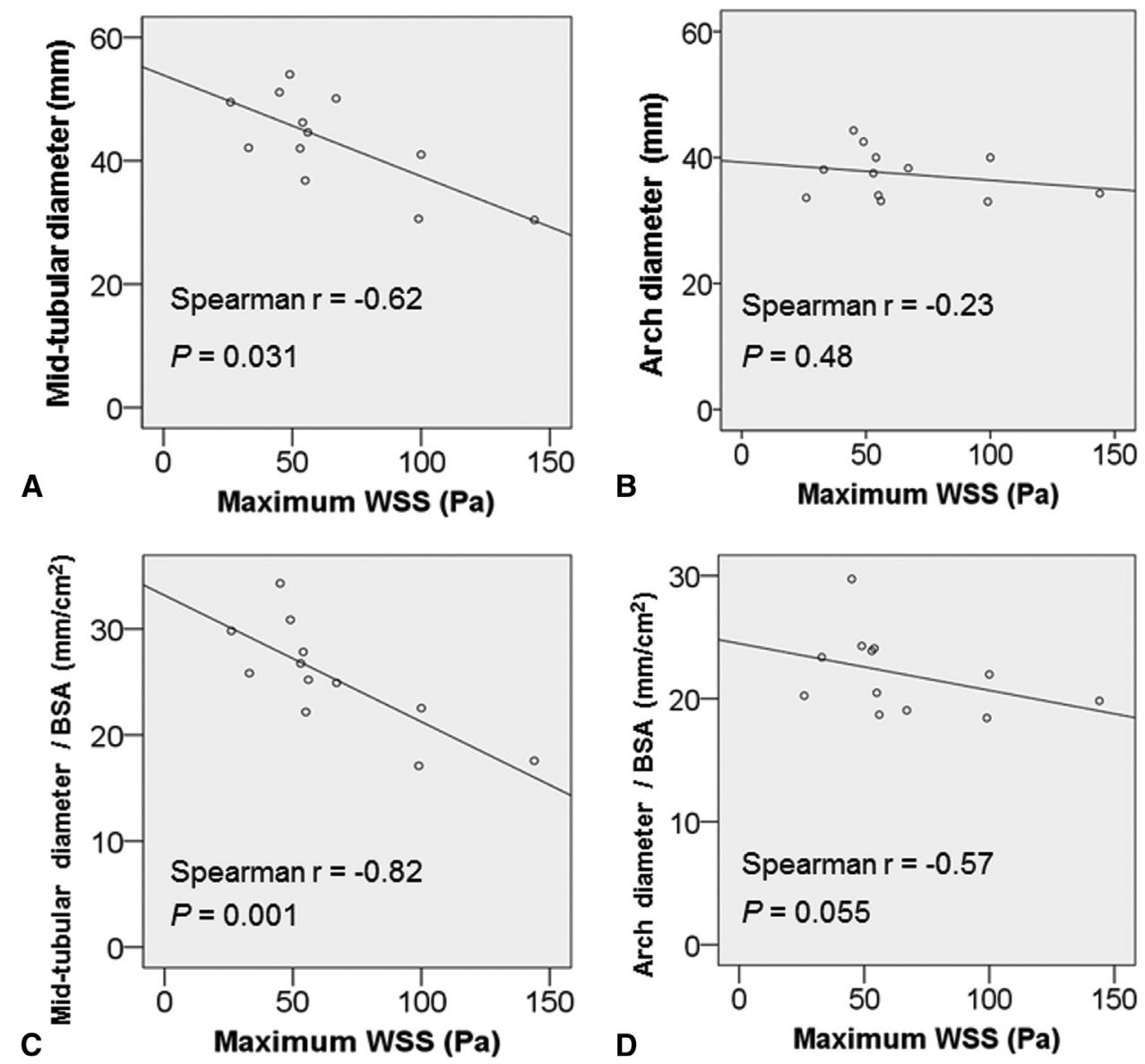

FIGURE 7. Correlation of maximum WSS and aortic diameter. Correlations between maximum WSS and unadjusted aortic diameter (A, B) or aortic diameter adjusted with BSA (C, D) are shown. Aortic diameters were measured at the mid-tubular ascending aorta (A, C) and aortic arch (B, D). WSS, Wall shear stress; $P a$, pascal; $B S A$, body surface area.

\section{Study Limitations}

Our study limitations include its size. The small number of BAV cases prevented quantitative comparisons of hemodynamic variables between the different cusp morphologies and the different aortic stenosis grades. In addition, the assumptions and approximations made in simulating blood flow could have affected the study results. Compliance of the aortic wall was not modeled, and the assumed rigidity could have resulted in overestimation of the WSS, although investigation based on both rigid wall models and compliant models has shown qualitatively similar distribution of WSS at the aorta during systole. ${ }^{28}$ In fact, lower aortic distensibility and greater stiffness have been found in BAV cases than in TAV cases, even after adjustments for aortic size and blood pressure. ${ }^{29}$ Inclusion of elasticity requires inclusion of the fluid-structure interaction and the material properties of the blood vessel and residual stress inside the aortic wall. At present, full acquisition of these data is not realistic. BAV orifice models were assumed to keep the same shape and size throughout a cardiac cycle. Because most patients included in our study had severe calcification, the rigid valve approximation can be considered acceptable. Flow in the aorta in the BAV cases was inherently turbulent because of the inflow jet created by the narrow aortic orifice. However, selection of an appropriate turbulence model is challenging because not a single, practical turbulence model can predict all turbulent flows with sufficient accuracy. Further difficulties in choosing turbulence models are posed. Intermittency, pulsatility, and transition between laminar flow and turbulence make simulating aortic flow challenging. Future studies that include larger numbers of patients with severe calcification of the aortic valve are needed to compare hemodynamics between different fusion types and to clarify the pathogenic hemodynamic factors in patients with BAV.

\section{CONCLUSIONS}

Patient-specific, CFD-based assessment of hemodynamics is clinically feasible. CFD simulation can be used for precise and detailed evaluation of hemodynamics in individual patients and will facilitate molecular 
biological investigation into the pathophysiology of aortic diseases.

\section{Conflict of Interest Statement}

Dr Misawa reports consulting fees from Terumo, Life Line Ltd, and Century Medical Ltd, as well as lecture fees from St. Jude Medical. All other authors have nothing to disclose with regard to commercial support.

The authors thank Yoshimasa Koyama and Kazunori Yamakoshi for technical assistance with the MRI measurements.

\section{References}

1. Ward C. Clinical significance of the bicuspid aortic valve. Heart. 2000;83:81-5.

2. Siu SC, Silversides CK. Bicuspid aortic valve disease. J Am Coll Cardiol. 2010; 55:2789-800.

3. Verma S, Siu SC. Aortic dilatation in patients with bicuspid aortic valve. $N$ Engl J Med. 2014;370:1920-9.

4. Della Corte A, Quarto C, Bancone C, Castaldo C, Di Meglio F, Nurzynska D, et al. Spatiotemporal patterns of smooth muscle cell changes in ascending aortic dilatation with bicuspid and tricuspid aortic valve stenosis: focus on cell-matrix signaling. J Thorac Cardiovasc Surg. 2008;135:8-18. e1-2.

5. Hope MD, Hope TA, Crook SE, Ordovas KG, Urbania TH, Alley MT, et al. 4D flow CMR in assessment of valve-related ascending aortic disease. JACC Cardiovasc Imaging. 2011;4:781-7.

6. Barker AJ, Markl M, Burk J, Lorenz R, Bock J, Bauer S, et al. Bicuspid aortic valve is associated with altered wall shear stress in the ascending aorta. Circ Cardiovasc Imaging. 2012;5:457-66.

7. Bissell MM, Hess AT, Biasiolli L, Glaze SJ, Loudon M, Pitcher A, et al. Aortic dilation in bicuspid aortic valve disease: flow pattern is a major contributor and differs with valve fusion type. Circ Cardiovasc Imaging. 2013;6:499-507.

8. Mahadevia R, Barker AJ, Schnell S, Entezari P, Kansal P, Fedak PW, et al. Bicuspid aortic cusp fusion morphology alters aortic three-dimensional outflow patterns, wall shear stress, and expression of aortopathy. Circulation. 2014;129:673-82.

9. Meierhofer C, Schneider EP, Lyko C, Hutter A, Martinoff S, Markl M, et al. Wall shear stress and flow patterns in the ascending aorta in patients with bicuspid aortic valves differ significantly from tricuspid aortic valves: a prospective study. Eur Heart J Cardiovasc Imaging. 2013;14:797-804.

10. Yamaguchi T, Ishikawa T, Tsubota K, Imai Y, Nakamura M, Fukui T. Computational blood flow analysis - new trends and methods. J Biomech Sci Eng. 2006;1: 29-50.

11. Morris PD, Narracott A, von Tengg-Kobligk H, Silva Soto DA, Hsiao S, Lungu A, et al. Computational fluid dynamics modelling in cardiovascular medicine. Heart. 2016;102:18-28.

12. Numata S, Itatani K, Kanda K, Doi K, Yamazaki S, Morimoto K, et al. Blood flow analysis of the aortic arch using computational fluid dynamics. Eur J Cardiothorac Surg. 2016;49:1578-85.

13. Isoda H, Ohkura Y, Kosugi T, Hirano M, Alley MT, Bammer R, et al. Comparison of hemodynamics of intracranial aneurysms between MR fluid dynamics using 3D cine phase-contrast MRI and MR-based computational fluid dynamics. Neuroradiology. 2010;52:913-20.

14. Wendell DC, Samyn MM, Cava JR, Ellwein LM, Krolikowski MM, Gandy KL, et al. Including aortic valve morphology in computational fluid dynamics simulations: initial findings and application to aortic coarctation. Med Eng Phys. 2013;35:723-35.

15. Jansen IG, Schneiders JJ, Potters WV, van Ooij P, van den Berg R, van Bavel E, et al. Generalized versus patient-specific inflow boundary conditions in compu- tational fluid dynamics simulations of cerebral aneurysmal hemodynamics. Am J Neuroradiol. 2014;35:1543-8.

16. Sievers HH, Schmidtke C. A classification system for the bicuspid aortic valve from 304 surgical specimens. J Thorac Cardiovasc Surg. 2007;133:1226-33.

17. Fazel SS, Mallidi HR, Lee RS, Sheehan MP, Liang D, Fleischman D, et al. The aortopathy of bicuspid aortic valve disease has distinctive patterns and usually involves the transverse aortic arch. J Thorac Cardiovasc Surg. 2008;135: 901-7. e1-2.

18. Kang JW, Song HG, Yang DH, Baek S, Kim DH, Song JM, et al. Association between bicuspid aortic valve phenotype and patterns of valvular dysfunction and bicuspid aortopathy: comprehensive evaluation using MDCT and echocardiography. JACC Cardiovasc Imaging. 2013;6:150-61.

19. Kari FA, Fazel SS, Mitchell RS, Fischbein MP, Miller DC. Bicuspid aortic valve configuration and aortopathy pattern might represent different pathophysiologic substrates. J Thorac Cardiovasc Surg. 2012;144:516-7.

20. Chen D, Muller-Eschner M, Kotelis D, Bockler D, Ventikos Y, von TenggKobligk H. A longitudinal study of Type-B aortic dissection and endovascular repair scenarios: computational analyses. Med Eng Phys. 2013;35: 1321-30.

21. Norgaard BL, Leipsic J, Gaur S, Seneviratne S, Ko BS, Ito H, et al; NXT Trial Study Group. Diagnostic performance of noninvasive fractional flow reserve derived from coronary computed tomography angiography in suspected coronary artery disease: the NXT trial (Analysis of Coronary Blood Flow Using CT Angiography: Next Steps). J Am Coll Cardiol. 2014;63:1145-55.

22. Kilner PJ, Yang GZ, Mohiaddin RH, Firmin DN, Longmore DB. Helical and retrograde secondary flow patterns in the aortic arch studied by. Circulation. 1993;88:2235-47.

23. Schnell S, Entezari P, Mahadewia RJ, Malaisrie SC, McCarthy PM, Collins JD, et al. Improved semiautomated 4D flow MRI analysis in the aorta in patients with congenital aortic valve anomalies versus tricuspid aortic valves. J Comput Assist Tomogr. 2016;40:102-8.

24. Masuda M, Kuwano H, Okumura M, Arai H, Endo S, Doki Y, et al. Thoracic and cardiovascular surgery in Japan during 2013: Annual report by The Japanese Association for Thoracic Surgery. Gen Thorac Cardiovasc Surg. 2015;63: 670-701.

25. Etz CD, von Aspern K, Hoyer A, Girrbach FF, Leontyev S, Bakhtiary F, et al. Acute type A aortic dissection: characteristics and outcomes comparing patients with bicuspid versus tricuspid aortic valve. Eur J Cardiothorac Surg. 2015;48: 142-50.

26. Allen BD, van Ooij P, Barker AJ, Carr M, Gabbour M, Schnell S, et al. Thoracic aorta 3D hemodynamics in pediatric and young adult patients with bicuspid aortic valve. J Magn Reson Imaging. 2015;42:954-63.

27. $2010 \mathrm{ACCF} / \mathrm{AHA} / \mathrm{AATS} / \mathrm{ACR} / \mathrm{ASA} / \mathrm{SCA} / \mathrm{SCAI} / \mathrm{SIR} / \mathrm{STS} / \mathrm{SVM}$ Guidelines for the Diagnosis and Management of Patients With Thoracic Aortic Disease Representative Members, Hiratzka LF, Creager MA, Isselbacher EM, Svensson LG; 2014 AHA/ACC Guideline for the Management of Patients With Valvular Heart Disease Representative Members., Nishimura RA, Bonow RO, Guyton RA, Sundt TM III. Surgery for aortic dilatation in patients with bicuspid aortic valves: a statement of clarification from the American College of Cardiology/American Heart Association Task Force on Clinical Practice Guidelines. J Thorac Cardiovasc Surg. 2016;151:959-66.

28. Crosetto P, Reymond P, Deparis S, Kontaxakis D, Stergiopulos N, Quarteroni A. Fluid-structure interaction simulation of aortic blood flow. Comput Fluids. 2011; 43:46-57.

29. Nistri S, Grande-Allen J, Noale M, Basso C, Siviero P, Maggi S, et al. Aortic elasticity and size in bicuspid aortic valve syndrome. Eur Heart J. 2008;29:472-9.

Key Words: bicuspid aortic valve, aortopathy, computational fluid dynamics, wall shear stress 


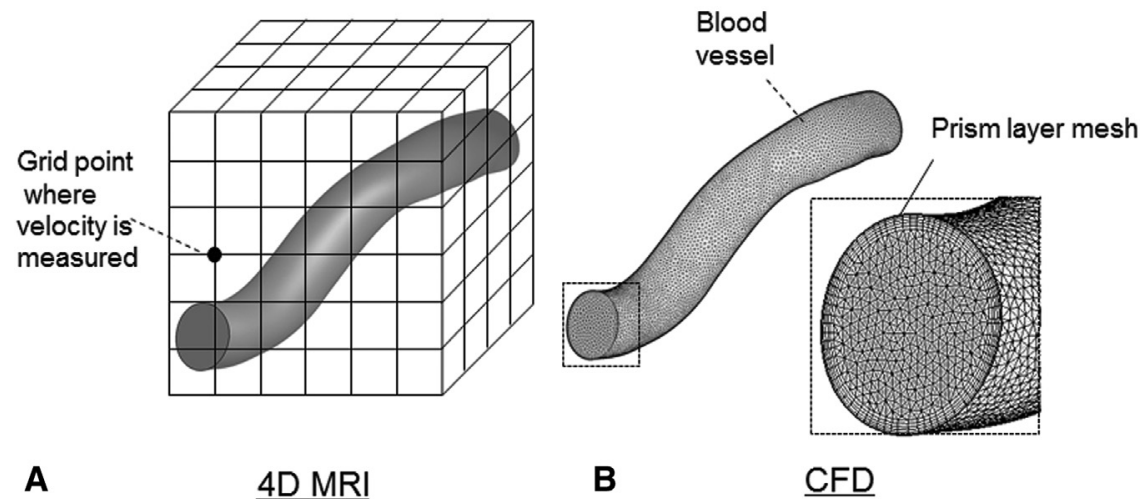

FIGURE E1. Diagram of MRI-based and CFD-based assessment of WSS. A, With MRI, points at which velocity data are obtained arrayed on a lattice grid. This type of grid results in unequal distances between the grid points and the vessel wall. B, With CFD, grid points used for the assessment of WSS can be positioned at an equal distance from the vessel wall with the use of boundary-fitted meshes. MRI, Magnetic resonance imaging; $C F D$, computational fluid dynamics.

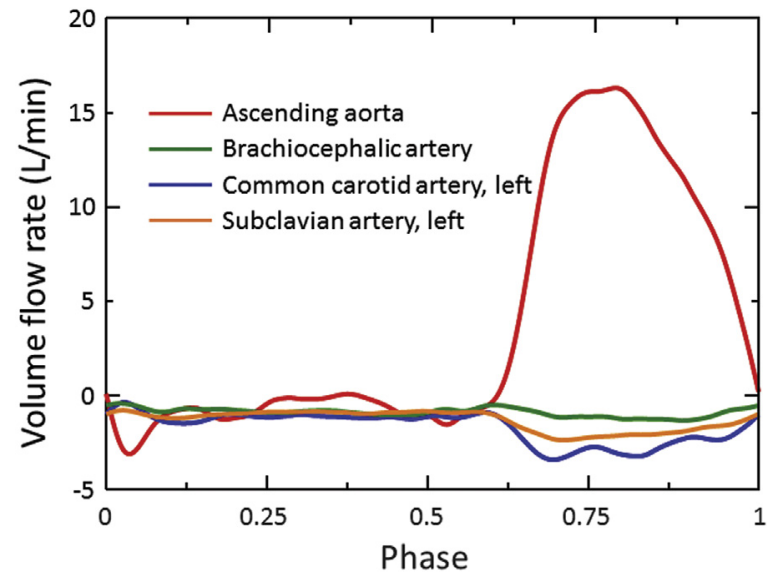

FIGURE E2. Representative flow rate curves showing the variations in flow rate measured at different time points. These variations are reflected in the simulation.

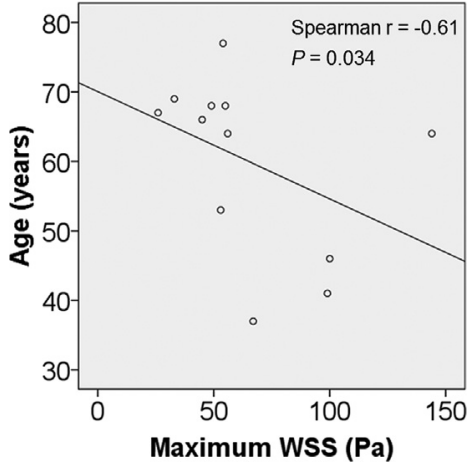

FIGURE E3. Regression line showing correlation between maximum WSS and age. WSS, Wall shear stress; $P a$, pascal. 


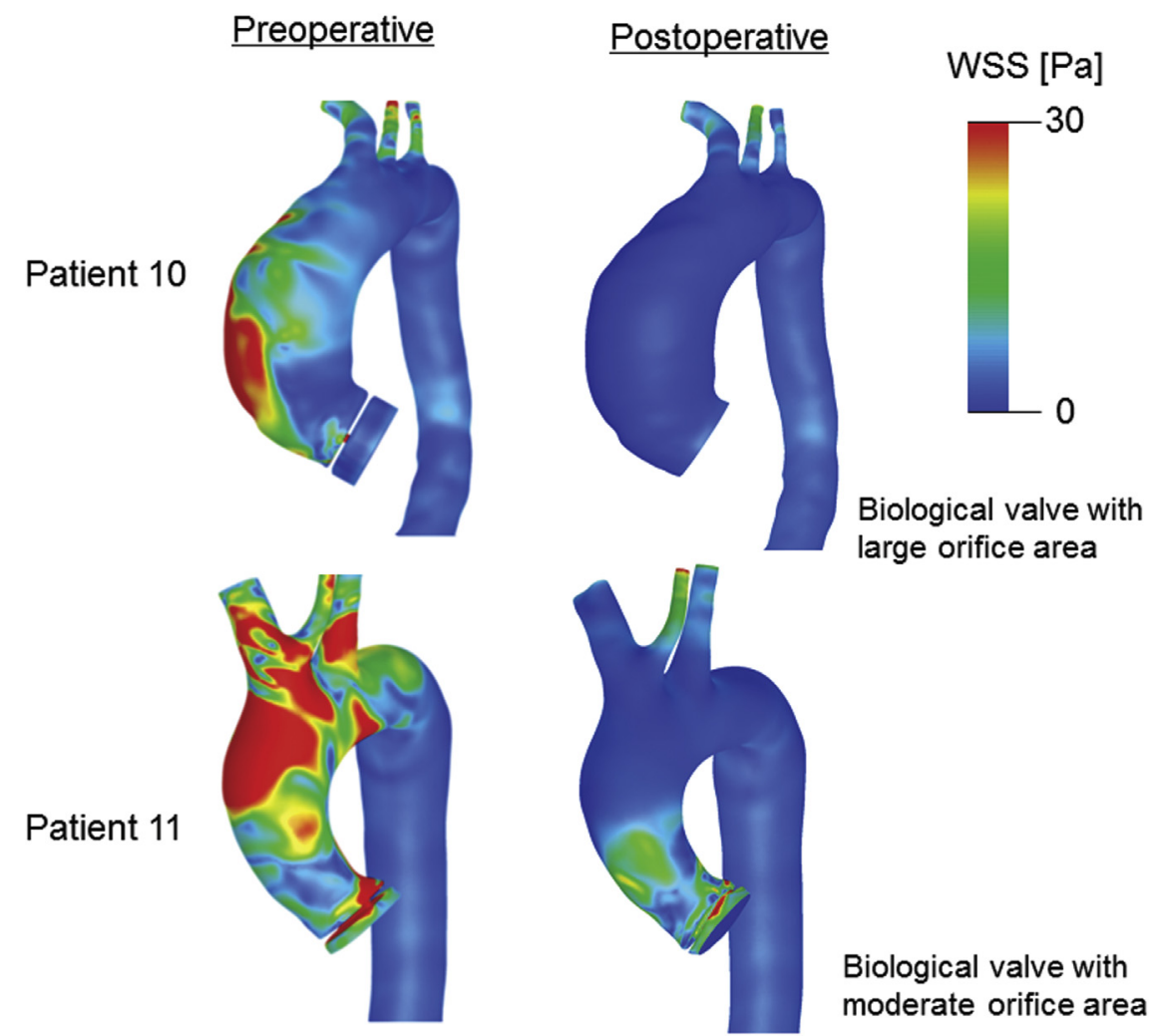

FIGURE E4. Simulation of WSS distribution after replacement with a biological aortic valve. Patients 10 and 11 represent those with bicuspid stenosis with and without aortic dilatation, respectively. WSS, Wall shear stress; $P a$, pascal. 
TABLE E1. General clinical, aortic, and valvular characteristics, per study group

\begin{tabular}{|c|c|c|c|}
\hline & $\begin{array}{c}\text { BAV } \\
(n=12)\end{array}$ & TAV $($ control) $(\mathbf{n}=\mathbf{3})$ & $P$ value \\
\hline Age, y & $60.6 \pm 12.6$ & $67.0 \pm 7.9$ & .38 \\
\hline Male sex & $9(75 \%)$ & $3(100 \%)$ & .87 \\
\hline Height $(\mathrm{cm})$ & $161.7 \pm 7.0$ & $173.7 \pm 4.0$ & .015 \\
\hline Weight (kg) & $63.8 \pm 11.0$ & $71.0 \pm 8.9$ & .32 \\
\hline $\operatorname{BSA}\left(\mathrm{m}^{2} / \mathrm{kg}\right)$ & $1.71 \pm 0.13$ & $1.89 \pm 0.13$ & .12 \\
\hline \multicolumn{4}{|l|}{ Aortic stenosis } \\
\hline None & $0(0 \%)$ & $3(100 \%)$ & $<.01$ \\
\hline Mild (mean $\triangle P<20 \mathrm{~mm} \mathrm{Hg}$ ) & $1(8 \%)$ & $0(0 \%)$ & 1.0 \\
\hline Moderate (mean $\triangle P \geq 20$ and $<40 \mathrm{~mm} \mathrm{Hg}$ ) & $2(17 \%)$ & $0(0 \%)$ & 1.0 \\
\hline Severe (mean $\triangle P \leq 40 \mathrm{~mm} \mathrm{Hg}$ ) & $9(75 \%)$ & $0(0 \%)$ & .087 \\
\hline \multicolumn{4}{|l|}{ Aortic insufficiency } \\
\hline None or trivial & $8(66 \%)$ & $2(67 \%)$ & 1.0 \\
\hline Mild & $2(17 \%)$ & $1(33 \%)$ & 1.0 \\
\hline Moderate & $1(8 \%)$ & $0(0 \%)$ & 1.0 \\
\hline Severe & $0(0 \%)$ & $0(0 \%)$ & 1.0 \\
\hline \multicolumn{4}{|l|}{ Aortic diameter (mm) } \\
\hline Aortic sinus & $35.3 \pm 3.5$ & $41.3 \pm 3.3$ & .062 \\
\hline Sinotubular junction & $34.2 \pm 9.0$ & $32.3 \pm 0.3$ & .74 \\
\hline Mid ascending aorta & $43.2 \pm 7.7$ & $37.7 \pm 3.3$ & .26 \\
\hline Transverse aortic arch* & $37.4 \pm 3.8$ & $31.6 \pm 7.6$ & .076 \\
\hline Descending aorta (tracheal bifurcation) & $27.1 \pm 2.1$ & $29.0 \pm 2.6$ & .23 \\
\hline \multicolumn{4}{|l|}{ Aortic diameter/BSA $\left(\mathrm{mm} / \mathrm{m}^{2}\right)$} \\
\hline Aortic sinus & $20.7 \pm 2.7$ & $22.3 \pm 3.1$ & .41 \\
\hline Sinotubular junction & $19.9 \pm 4.4$ & $17.4 \pm 1.3$ & .35 \\
\hline Mid-ascending aorta & $25.4 \pm 5.6$ & $20.3 \pm 2.0$ & .15 \\
\hline Transverse aortic arch* & $22.0 \pm 2.8$ & $17.1 \pm 4.6$ & .036 \\
\hline Descending aorta (tracheal bifurcation) & $15.9 \pm 2.1$ & $15.4 \pm 1.9$ & .65 \\
\hline NYHA classification & $2.0 \pm 0.42$ & 1.0 & $<.01$ \\
\hline $\operatorname{LVDD}(\mathrm{mm})$ & $48.9 \pm 6.5$ & $45.0 \pm 6.9$ & .37 \\
\hline LVDS (mm) & $30.4 \pm 7.2$ & $30.7 \pm 2.6$ & .95 \\
\hline LVEF (\%) & $68.3 \pm 7.5$ & $66.3 \pm 6.1$ & .67 \\
\hline
\end{tabular}

